\title{
Percepção Ambiental no Sertão Cearense: Estudo de Caso na Comunidade Santa Maria, Ererê.
}

\author{
Environmental Awareness in the Hinterland Cearense: Case Study in Community Santa \\ Maria, Ererê.
}

\author{
Albuquerque $^{1}$, D. S.; Nonato $^{2}$, R. P. P. M.; Medeiros ${ }^{3}$, J. F.
}

Diealbuquerque07@gmail.com;

\begin{abstract}
Resumo
Para conviver com as duras secas que castigam a região semiárida do Nordeste brasileiro, a construção de açudes tem sido, historicamente, uma importante estratégia atenuante contra as severas estiagens, mudando a vida de quem reside próximo a esses reservatórios. Dentro dessa perspectiva, esse trabalho objetiva apresentar a percepção ambiental dos moradores da comunidade Santa Maria, município de Ererê-CE, acerca do açude Santa Maria e da relação homem-açude existente. A pesquisa envolveu a realização de entrevistas semiestruturadas com 11 (onze) famílias residentes na comunidade supracitada. Os resultados mostram que a população residente na comunidade Santa Maria demonstra grande preocupação com a degradação e uso do reservatório. Contudo, a população percebe que algumas atividades desenvolvidas no reservatório afetam a qualidade da água, representando danos que comprometem o ambiente e a vida dos moradores locais, necessitando assim, da prática de sensibilização pelos pescadores e de maior fiscalização pelos órgãos competentes.
\end{abstract}

\begin{abstract}
To live with the dry hard to punish the semiarid region of Northeast Brazil, the construction of dams has historically been an important mitigating strategy against severe droughts, changing the lives of those who live near these reservoirs. From this perspective, this study aims to present the environmental awareness of the residents of the rural community site Santa Maria, municipality of Ererê-CE on the weir Santa Maria and the existing manweir relationship. The research involved conducting semistructured interviews with eleven (11) families living in the aforementioned community. The results show that the resident population in the community Santa Maria shows great concern for the degradation and use of the reservoir. However, the population realizes that some activities in the reservoir affect water quality, representing damages that compromise the environment and the lives of local residents in need as well, the practice of awareness by fishermen and greater oversight by the competent bodies.
\end{abstract}

Keywords: Environmental Awareness. Weir. Survival.

Palavras-chave: Percepção ambiental. Açude. Sobrevivência.

\section{INTRODUÇÃO}

A região semiárida do Nordeste brasileiro compreende uma área de 982.563,3 km², abrangendo os estados do Piauí, Ceará, Rio Grande do Norte, Paraíba, Pernambuco, Alagoas, Sergipe, Bahia e parte do norte de Minas Gerais (Região Sudeste). De acordo com Silva et al. (2010) apresenta precipitação anual máxima de $800 \mathrm{~mm}$, insolação média de 2.800 h.ano ${ }^{-1}$, temperaturas médias anuais de $23^{\circ} \mathrm{C}$ a $27^{\circ} \mathrm{C}$, evaporação média de $2.000 \mathrm{~mm}$.ano ${ }^{-1}$ e umidade relativa do ar média em torno de 50\%. Percebe-se que as características climáticas da região semiárida, tornam-na bastante susceptível aos efeitos de prolongadas secas que se reproduzem ao longo do tempo, em volume de água insuficiente nos mananciais, para atender a demanda hídrica populacional.

\footnotetext{
${ }^{1}$ Diêgo Souza Albuquerque, discente do Curso de Geografia, CAMEAM-UERN, Pau dos Ferros-RN, Brasil

${ }^{2}$ Raiany Priscila Paiva Medeiros Nonato, discente do Curso de Geografia, CAMEAM-UERN, Pau dos Ferros-RN, Brasil

${ }^{3}$ Jacimária Fonseca de Medeiros, discente do Curso de Geografia, CAMEAM-UERN, Pau dos Ferros-RN, Brasil
} 
Diversas foram as políticas públicas de investimento governamental para o combate do efeito das secas regionais. Dentre elas, a política de construção de açudes a partir de investimentos públicos, na região Nordeste, com início no ano de 1890. Essa política ganha mais força com a criação do Departamento Nacional de Obras contra as Secas (DNOCS) (Assunção e Livingstone, 1993).

A construção desses reservatórios para captação e armazenamento de água revitaliza aqueles que a podem utilizar, desenvolver suas atividades ligadas ao abastecimento, usos domésticos, aproveitamento de vazantes, cultivos, dessedentação de animais e outros usos diversos. Segundo Molle (1994), a questão da água (falta dela) foi/é o "âmago" de uma problemática: o pavor das secas que historicamente acometem o Nordeste, sendo assim, resta ao homem aproximar-se das águas retidas advindas dos escoamentos.

Tendo em vista a disponibilidade hídrica acarretada pelos açudes, é comum, em suas margens, o desenvolvimento de atividades que necessitem, além da água, do uso do solo, para, por exemplo, cultivar vazantes, desenvolvimento da agricultura e pastagem. Essas atividades antrópicas de uso e ocupação de solo, transformação de recursos naturais representam as estruturas desenvolvidas e apresentadas pelo homem, ao longo do tempo, como forma de suprir suas necessidades básicas de produção e sobrevivência (Silva, 2011).

De acordo com IBGE (2013), o uso da terra geralmente está associado à atividades conduzidas pelo homem relacionadas com uma extensão de terra ou um ecossistema. Podendo ser entendido como uma série de operações desenvolvidas pelos homens, com a intenção de obter produtos e benefícios, através do uso dos recursos da terra com função socioeconômica (agricultura, habitação, proteção ambiental) da superfície básica.

Quando atrelamos a discussão sobre o uso da terra à área de um açude, em especial em suas margens, é fundamental a preocupação e o planejamento com as atividades que aí são/serão desenvolvidas, principalmente quando a água deste reservatório é/for utilizada para abastecimento humano. O reconhecimento do valor da água ou a forma como este recurso é visto e entendido pelas populações faz parte de uma discussão alcançada pela percepção ambiental, definida por Fernandes, et al, (2004) como capaz de avistar a concepção que as pessoas tem acerca do ambiente em que vivem e da natureza a sua volta, sendo variável de indivíduo para indivíduo, pois cada pessoa reflete de forma diferente sobre o ambiente em que vive, respondendo e manifestando seu entendimento e expectativas que podem ser resultadas de percepções individuais ou coletivas. Segue afirmando que “[...] o estudo da percepção ambiental é de fundamental importância para que possamos compreender melhor as inter-relações entre o homem e o ambiente, suas expectativas, anseios, satisfações e insatisfações, julgamentos e condutas.” (FERNANDES et al, 2004, p. 1). 
Tendo em vista as notas introdutórias sobre as especificidades regionais acerca da questão hídrica, da política de açudagem como uma forma minimizadora dos impactos negativos, bem como o uso deste recurso sob a ótica das comunidades do entorno, o presente trabalho objetiva apresentar a percepção ambiental dos moradores da comunidade rural Santa Maria, município de Ererê-CE, acerca do açude Santa Maria.

O município de Ererê (Figura 01) pertence ao território cearense, situado na Mesorregião Vale do Jaguaribe e na Microrregião da Serra do Pereiro (IPECE, 2008).

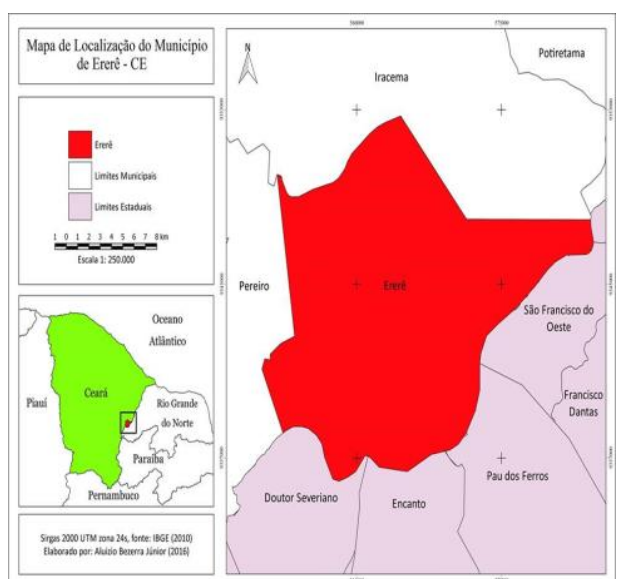

Figura 01. Localização do município de Ererê-CE. Fonte: IBGE (2010) elaborado por BEZERRA JUNIOR (2016), software Qgis 2.12.3.

O açude Santa Maria (Figura 02) pertence a sub-bacia hidrográfica do Médio Jaguaribe. Suas obras foram financiadas por recursos estaduais, tendo capacidade para armazenar $5.899 .800 \mathrm{~m}^{3} \mathrm{de}$ água (SHR, 2015), monitorada pela Companhia de Gestão dos Recursos Hídricos (COGERH), (CEARÁ, 2009).

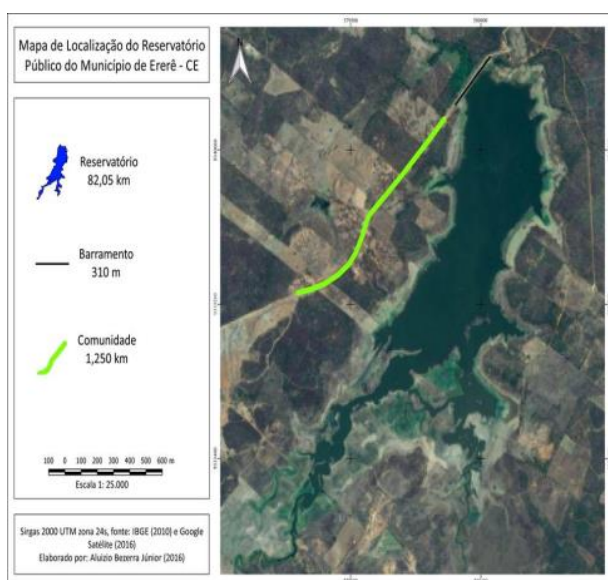

Figura 02. Localização do açude Santa Maria, Ererê-CE. Fonte: Google Earth, adaptado por BEZERRA JUNIOR (2016). 


\section{METODOLOGIA}

Para o desenvolvimento do presente trabalho foi realizado, inicialmente, aprofundamento teórico em autores como Assunção e Livingstone (1993), Molle e Dacier (1992), Silva et al (2010), Silva (2011) e Fernandes et al (2004).

Logo após, iniciaram-se os trabalhos de campo no açude Santa Maria e na comunidade Santa Maria, numa perspectiva exploratória, sendo possível mensurar a área de nossa pesquisa, in lócus. Essa pesquisa envolveu a realização de entrevistas semiestruturadas, aplicadas em julho de 2016, com 11 (onze) famílias, o que corresponde a 55\% dos núcleos familiares residentes na comunidade Santa Maria.

A primeira parte da entrevista constituiu-se de questões referentes ao perfil socioeconômico das famílias entrevistadas e na segunda parte foram lançados questionamentos sobre tempo de residência na comunidade e da relação homem-açude, abordando: comparativos entre o antes e depois do açude em uma perspectiva espaço-temporal, assim como a importância do mesmo; usos e ocupação do solo as margens do reservatório; o destino dado a água, e por fim, direcionamos as questões para compreensão da percepção ambiental dos moradores acerca de possíveis danos causados ao reservatório Santa Maria, bem como as possíveis soluções avistadas.

A organização de nossos resultados se encontra descrita em categorias de análise baseadas em Dictoro e Hanai (2016). As categorias de análise dos autores citados que nos serviram de base para a disposição dos resultados da presente pesquisa são: relações da água com Crenças/religiosas; relações de respeito e afetividade pela/com água; percepção dos impactos e poluição na água; relações de conhecimentos tradicionais/saberes locais e a água; relações de ações de conservação e a água e a percepção do Rio Mogi-Guaçu, região de Cachoeiras de Emas-SP.

\section{RESULTADOS E DISCUSSÃO}

Após aplicação da metodologia supracitada na busca da percepção ambiental e da compreensão da relação homem-açude construída pelos residentes da comunidade Santa Maria, Ererê-CE, os resultados obtidas nas entrevistas foram organizadas em categorias: $1^{\circ}$ - Tempo de residência dos moradores na comunidade, mudanças ocorridas no ecossistema levando-se em conta espaço e tempo e importância do reservatório; $2^{\circ}$ - Usos e ocupação do solo às margens do reservatório e o destino dado à água e $3^{\circ}$ - Percepção ambiental dos moradores acerca dos danos causados ao reservatório Santa Maria.

$1^{0}$ - Tempo de residência dos moradores na comunidade, mudanças ocorridas no ecossistema levando-se em conta espaço e tempo e importância do reservatório. 
Os questionamentos proposto na $1^{\circ}$ categorias foram: Há quanto tempo você/sua família reside na área do entorno do reservatório? Comparando o antes e depois da construção do açude Santa Maria, quais as mudanças na vida de vocês? Qual a importância do açude em sua visa?

As famílias entrevistadas residem na comunidade desde antes da construção do açude Santa Maria, ou seja, desde antes de 1999. Em seu relato, a senhora Lenici Martins afirma:

"Porque a gente morava do outro lado do açude, aí quando ele foi construído falaram que quando ele enchesse, a água ia na nossa casa, só que no caso nem foi, era melhor que a gente tivesse ficado lá do outro ladinho que a água tinha ficado mais pertinho ainda, né?!... Mas aí a gente passou pra cá [...]”.

"O açude representa uma das soluções que o sertanejo vem opondo ao flagelo das secas[...]" (MOLLE e DACIER, 1992, p. 24). A relevância do açude na vida de um ribeirinho pode ser realmente sentindo e entendida quando passamos a conviver com essas pessoas e investigar seu cotidiano, dessa forma, compreendendo a relação homem-açude construída. Tal relevância encontra maior significado quando o açude se encontra numa área propensa à secas constantes, visto que a irregularidade de chuvas castiga o sertanejo, sendo assim o açude é um baluarte, um suporte de convívio com as secas.

Ao ouvir os relatos dos moradores da comunidade comparando o antes e depois da construção do açude, podemos averiguar a importância que essa obra surtiu na vida dos entrevistados. A moradora Maria Huga relata que:

“Ah, bom demais, maravilha! Por que antes a gente vivia à custa da agua de cacimbão, em 98 foi uma seca muito grande e depois que fez esse açude foi só benção, depois que ele foi feito tem essa adutora, além de nós ter o açude tem a vazante para o povo plantarem, ah ter a adutora que é muito bom, a gente tem água encanada e nunca falta, graças à Deus é uma benção.”

$\mathrm{O}$ agricultor Fernando Gomes descreve sua reflexão apontando fatos de sua vida: "Mudou, depois da bem feitoria do açude mudou muito, né?! Hoje aqui o açude Santa Maria se tornou uma fonte de riqueza para muita gente, muita gente depende e sobrevive dele, da pesca, da própria água, né?! Da plantação de capim, que o pessoal vai tirando a sobrevivência. Ele tem um meio muito sustentável, né, principalmente aqui na bacia, antes dele aqui as águas era difícil. Não teve um cabra pra botar mais água na cabeça que eu, me levantava uma hora da manhã hoje não, né, água é encanada, tem água na torneira, né [...] a água na torneira, né, quer dizer: mudou muito pra quem ia de madrugada, meio dia buscar água na cacimba melhorou muito, tudo ficou mais fácil. Melhorou hoje tem os pescadores, né [...]."

$\mathrm{O}$ açude como suporte para atenuar os castigos da seca sempre é relatado pelos moradores. O senhor Leonidas Paulo relata: "Foi muito bom, por ter água e muito peixe aí quando a gente pesca. 
Melhorou muito, esse açude aqui foi um minério, de primeiro aqui era seco, em 93 aqui foi luta pra escapar por conta da seca sem água [...]”.

Alguns moradores da comunidade relatam que após a construção do açude puderam desenvolver atividades pecuárias sem muito esforço, tendo em vista a disponibilidade hídrica. Além das atividades de agricultura, com plantações nas áreas das vazantes, as margens do reservatório, propiciando colheitas para o consumo. Segundo Carlos Gomes:

"Sem o açude não tava bom não, por que a gente tava próximo de cavar poço, cacimbão para dar água ao gado, o açude melhorou pra fazer campineira, né, criar o gado, tem a água encanada da adutora. Se não fosse o açude nós não era nada, a única coisa aqui que nós tem de importante aqui em Santa Maria é esse açude. Sem água nós não somos nada."

Francisca Ferreira ressalta que: "Melhorou muito, porque sempre a gente tem uma vazantinha de feijão tem um capim para dar a um bichinho que a gente cria, aí a gente planta uma vazantinha."

Sobre o exposto, é nítida a importância que o açude Santa Maria tem na vida das famílias entrevistadas. Além da água disponível e da área para pesca, os moradores desenvolvem suas vazantes, seja destinada ao consumo animal, seja para o consumo humano, que são meios de sobrevivência no local, princípios básicos da sustentabilidade.

Sobre a importância do reservatório, a pescadora Francisca Damiana relata:

“Assim, tem a sobrevivência, por que a água é mais fácil e tem os peixes para a gente pescar, né, a gente as vezes planta uma vazante, colhe o feijão. Só em a gente ter água pra nós e para os animais... e água tá ficando difícil por aí.”

O agricultor Fernando Gomes diz: "A sobrevivência, hoje a gente tem o açude aí, e se não secar só tem a melhoras, por isso o açude foi de grande importância."

\section{$2^{\circ}$ - Usos e ocupação do solo às margens do reservatório e o destino dado à água}

Nessa categoria são abordado os resultados dos seguintes questionamentos: De que forma foi obtida a posse dessas terras a margem do açude Santa Maria? Quais as atividades são desenvolvidas por você/Sr./Sra. às margens do reservatório? Se cultiva as terras, quais os tipos de plantações? É feito uso de agrotóxicos no processo de cultivo? Quais os tratos dados ao solo? (Aração tradicional ou mecânica, queimadas, adubação) Quais os destinos dados por você (s) a água do açude?

Conforme visto na seção anterior, alguns moradores da comunidade desenvolvem suas atividades, nas margens do Açude Santa Maria. No entanto, este uso não é feito por todos os moradores, pois nem todos tem posse das terras, o que se agrava ainda mais em virtude da falta de um esquema de consorciação entre todos os moradores. Tal fato elucida alguns conflitos pelo uso, que torna-se nítido na fala de moradores que reclamam da posse indevida das margens do açude por 
outros moradores, tendo vista que o reservatório é público e que todos os antigos donos das terras nas quais situa-se o açude foram indenizados pelas terras que seriam submersas a posteriori.

Com relação às atividades desenvolvidas nas margens do reservatório pelos entrevistados, apontam como principal a agricultura de subsistência, cultivando feijão, milho e alguns legumes. A senhora Francisca Ferreira relatou que:

“Cultiva milho e feijão e as vezes a melancia e o melão”. No relato de Neci Barreto, quando questionado os tipos de cultivos, averiguamos alguns: “[...] planta batata e feijão [...]."

Os entrevistados também apontam o desenvolvimento de vazantes para a alimentação de animais, através do plantio de capim, milho e sorgo forrageira.

A agricultora Lenici Martins conta: "Cria umas reis e planta capim, uma forrageirinha animal."

O agricultor Fernando Gomes enfatiza que: "Planta mais a forragem animal, né, o capim [...]."

Sobre a forma como o solo é utilizado nas plantações, percebe-se nitidamente que há diferença entre o universo amostral. Na descrição da agricultora Maria Huga percebemos a forma tradicional que realiza suas atividades de plantio:

"Pra plantar a água vai secando e a gente vai tirando os garranchos secos que vai ficando, aí a gente vai limpando e jogando fora [...] e planta e quando nasce o mato a gente limpa."

O senhor Carlos Gomes, por sua vez faz, mencionou fazer uso de algumas ferramentas: “Uso trator e capinadeira, porque não dá pra plantar sem cultivar porque se não, não dá nada. Tem que mexer a terra e adubar, a gente só não bota veneno porque não pode."

Vale ressaltar que o uso de insumos agrícolas esteve ausente nas falas de todo o universo amostral.

A percepção quanto ao destino das águas do reservatório se mostrou diverso. Os entrevistados mencionaram que usam a água para satisfazer suas necessidades básicas diárias de consumo doméstico, como asseio, preparo de alimentos e lavagem de pratos e roupas. Além do uso doméstico, a água do açude Santa Maria é destinada à dessedentação animal, irrigação de pequenos sítios de frutas, cultivo de vazantes e pesca. Os moradores relatam que atualmente não usam a água para o consumo humano, em virtude do atual nível do açude comprometer as suas propriedades físicas e químicas, tornando imprópria para tal finalidade. Em suas falas destacam que a água que chega nas residências apresenta cheiro forte e cor turva.

\section{$3^{\circ}$ - Percepção ambiental dos moradores acerca dos danos causados ao reservatório Santa}

\section{Maria}

As perguntas que propiciaram discussões e resultado nessa categoria são descritas: Você acredita que de alguma forma suas ações/atividades e de outras pessoas no entorno do reservatório pode prejudicar o solo ou a água desse reservatório? Existe algumas medidas utilizadas por você ou pela 
comunidade com o objetivo de amenizar os impactos provocados pelas atividades desenvolvidas nesse ambiente?

Os resultados da pesquisa mostram a percepção ambiental dos entrevistados sobre os danos que a comunidade causa ao açude Santa Maria. Para a moradora Maria Huga, os moradores causam danos ao reservatório:

"Prejudica sim, porque eles colocam o gado dentro do açude, outros desmatam perto, outros queimam e não pode haver isso, é errado fazer isso."

O morador Fernando Gomes afirma: Sim, no caso do veneno por exemplo, ne. O desmatamento também, né, que não pode, porque você sabe que temos que preservar a natureza, ne."

A moradora Lenici Ferreira firma:

"Quando ele tá cheio por exemplo, o povo fica lavando roupa dentro dele, aí eu ficava só reclamando porque eu não faço ai eu digo, devia os outros não fazer também, porque aí vai poluindo. Mas também isso acontecia quando não tinha água encanada, aí agora a gente tem, né."

A pescadora Francisca Damiana relata que:

"Se botar animal no beiço da água e mexer com tarrafa, que não pode, na época que não pode pescar e os pescadores querem pescar, aí a agua fica ruim porque já não é muita, tá ficando pouca!"

O morador Carlos Gomes descreve: "Se eles não respeitarem as normas que a COGERH botou, assim porque é como eu falei, todo mundo tem que plantar só capim, não pode plantar feijão e nem usar veneno."

A moradora Jannara Paulo relata que: "Os pescadores que vem de fora tem dias que eles batem muito na água para pescar e como o açude tá secando, tem dias que a água vem puro peixe.”

O senhora Neci Barreto confirma a versão da moradora Jannara Paulo afirmando que: "Rapaz, agora mesmo o que eles tão fazendo aí, tem prejudicado porque eles vem bate, bate na água para poder pescar, aí quando é de manhazinha a agua tá toda barreta."

Os relatos descritos acima demonstram a principal preocupação dos moradores da comunidade, a qualidade e zelo com a água do reservatório. Para esses moradores a água é sobrevivência, é necessária em todas as suas atividades diárias, e se em algum momento o açude secar será um problema drástico para os mesmos. Sendo assim é imprescindível preservar esse bem. Os moradores são cientes da necessidade de conservação do recurso hídrico, mas, segundo os mesmos, muitos pescadores que vem de fora da comunidade não enxergam essa necessidade, chegando a afetar a qualidade da água do açude que chega nas residências da comunidade.

Sobre produzir e preservar o ambiente em que vivem e trabalham, uma ação encontrada na comunidade merece destaque. Segundo os moradores, existe orientação da Companhia de Gestão 
dos Recursos Hídricos (COGERH) para que não seja plantado feijão as margens do reservatório para que não seja preciso o uso de agrotóxicos. Na pesquisa, alguns agricultores relataram que plantam o feijão em suas vazantes, no entanto, não fazem o uso de agrotóxicos, e sim de um inseticida natural. A agricultora Maria Huga nos esclarece que:

"Plantamos milho e feijão só que era muito complicado porque a gente não pode pulverizar com o veneno, aí tem a perseguição dos bichos, né, pássaros, lagartas... essas coisas assim, e a gente só combate fazendo a preparação com a folha do nim para expulgar o veneno. Assim eu tenho essa consciência [...]."

\section{CONSIDERAÇÕES FINAIS}

O trabalho realizado demostrou que os moradores da comunidade rural Sítio Santa Maria, município de Ererê-CE, atribuem valor simbólico ao açude Santa Maria, pois segundo os residentes, o açude mudou a vida de quem ali vive, sendo ressaltado que antes da construção do reservatório sofriam com a escassez de agua e hoje fazem uso deste recurso para diversos fins.

Além da percepção do valor simbólico, os moradores conseguem perceber que ações coletivas e individuais no entorno do reservatório podem prejudicar o açude e a vida das pessoas que dele usufruem, sendo perceptível em muitas falas, as mudanças ocorridas no reservatório o longo do tempo, principalmente referentes à qualidade da água.

Mediante o exposto evidenciamos a necessidade de práticas efetivas para sensibilização ambiental local na comunidade Santa Maria, assim como, maior fiscalização, pelos órgãos competentes, das atividades desenvolvidas nas margens do reservatório.

\section{REFERÊNCIAS}

ASSUNÇÃO, L. M.; LIVINGSTONE, I. Desenvolvimento inadequado: construção de açudes e secas no sertão do Nordeste. Revista Brasileira de Economia. Rio de Janeiro, v. 47, n. 3, p. 425 448 jul./set. 1993. Disponível em: < http://bibliotecadigital.fgv.br> Acesso em 16/06/2016.

CEARÁ, Assembleia Legislativa. Caderno Regional da sub-bacia do Médio Jaguaribe/Conselho de Altos Estudos e Assuntos Estratégicos. Fortaleza: INESP, 2009. Disponível em: < http://tmp.mpce.mp.br> Acesso em: 25/05/2016.

CRUZ NETO, O. O Trabalho de Campo como Descoberta e Criação. In MINAO, M. C. de S. (Org.). Pesquisa Social - Teoria, Método e Criatividade. $18^{\circ}$ ed. Petrópolis/RJ: Vozes, 2011, p. 51-66.

DICTORO, V. P.; HANAI, F. Y. Análise da relação homem-água: a percepção ambiental dos moradores locais de Cachoeira de Emas - SP, bacia hidrográfica do Rio Mogi-Guaçu. Revista Ra' 
e Ga. Curitiba, v. 36, p. 92-120, Abr/2016. Disponível em: <www.ser.ufpr.br/raega> Acesso em: 02/07/2016.

FERNANDES, R. S.; SOUZA, V. J.; PELISSARI, V. B.; FERNANDES, S. T. Uso da percepção ambiental como instrumento de gestão em aplicações ligadas às áreas educacional, social e ambiental. 2004. Disponível em: 〈http://www. anppas.org.br> Acesso em: 15/06/2016.

IBGE. Manual Técnico de Uso da Terra. 2. ed., Rio de Janeiro: IBGE, 2006.

IPECE. Instituto de Pesquisa e Estratégia Econômica do Ceará. Secretaria do Planejamento e Gestão (SEPLAG). Perfil Básico Municipal, Ererê. Fortaleza-CE, 2008. Disponível em: <http://www.ipece.ce.gov.br> Acesso em: 11/06/2016.

GOOGLE EARTH, 2016. Disponível em: 〈http://earth.google.com/〉.

MOLLE, F. Marcos históricos e reflexões sobre a açudagem e seu aproveitamento. Recife: SUDENE -DPG, 1994.

MOLLE, F.; CADIER, E. Manual do pequeno açude: construir, conservar e aproveitar pequenos açudes no Nordeste brasileiro. Recife: SUDENE-DPG, 1992.

SILVA, P. C. G.; MOURA, M. S. B.; KIILL, L. H. P.; BRITO, L. T. L.; PEREIRA, L. A.; SÁ, I. B.; CORREIA, R. C.; TEIXEIRA, A. H, C.; CUNHA, T. J. F.; FILHO, C. G. Caracterização do Semiárido brasileiro: fatores naturais e humanos. In: SÁ, I. B.; SILVA, P. C. G. (Editores Técnicos). Semiárido Brasileiro: pesquisa, desenvolvimento e inovação. Petrolina: Embrapa Semiárido, 2010. cap. 1, p. 17-48.

SILVA, R. V. da. Uso e ocupação da margem esquerda do rio Paraguai e a percepção ambiental de usuários do município de Cáceres, Mato grosso. Cáceres: UNEMAT, 2011. 109f. Dissertação (Mestrado em Ciências Ambientais) - Universidade do Estado do Maro Grosso, Cáceres/MG, 2011.

SRH. Secretaria de Recursos Hídricos do Ceará. Atlas Eletrônico dos Recursos Hídricos do Ceará. SIRN/CE, Jan/2015. Disponível em: < http://atlas.srh.ce.gov.br > Acesso em: 02/06//2016.

\section{AGRADECIMENTOS}

Nossos agradecimentos aos moradores da comunidade Santa Maria, que nos permitiram adentrar em vosso universo, dando-nos, na maioria dos casos, exímios exemplos de uma relação harmoniosa e saudável entre o homem e o seu ambiente.

Recebido em: 14/08/2016

Aceito para publicação em: 01/10/2016 